\title{
Risk Factors of Type 2 Diabetes among Maasai Pastoral Communities in Simanjiro,
} Tanzania

\author{
Juliana Mandha1, Buza Joram², Neema Kassimu², Pammla Petrucka ${ }^{3^{*}}$ \\ ${ }^{1}$ Department of Food and Nutritional Sciences, School of Life Sciences and Bioengineering, Science Nelson \\ Mandela African Institute of Science and Technology, Arusha, Tanzania \\ ${ }^{2}$ Department of Food and Nutritional Sciences, School of Life Sciences and Bioengineering, Nelson Mandela \\ African Institute of Science and Technology, Arusha, Tanzania \\ ${ }^{3}$ College of Nursing University of Saskatchewan, Saskatoon, Canada \\ Email:mandhaj@nmaist.ac.tz,buzaj@nmaist.ac.tz, kassimn@nmaist.ac.tz, \\ *pammla.petrucka@usask.ca
}

Received 22 October 2015; accepted 6 November 2015; published 13 November 2015

Copyright (C) 2015 by authors and OALib.

This work is licensed under the Creative Commons Attribution International License (CC BY). http://creativecommons.org/licenses/by/4.0/

(c) (i) Open Access

\begin{abstract}
Background: The prevalence of non-communicable diseases in particular diabetes is rising worldwide especially in low income countries. Information on the risk factors at the community level is of paramount importance to enable strategic preventive programs. This study is undertaken to investigate the prevalence of Type 2 diabetes and Impaired Fasting Glucose and associated risk factors among Maasai communities of Simanjiro District, Tanzania. Methods: This is a crosssectional population based study. Information on the risk factors is obtained using the World Health Organization STEPWISE approach. Target group are Maasai adults aged 25 years and above living in Simanjiro District. Descriptive statistics is used to explore prevalence and risk factors of Type 2 diabetes and impaired fasting glucose. Type 2 diabetes is defined as fasting blood glucose $\geq$ $7.0 \mathrm{mmol} / \mathrm{L}$ and/or being on diabetic medication. Impaired Fasting Glucose is defined as fasting blood glucose between 5.6 and $6.9 \mathrm{mmol} / \mathrm{L}$. Pearson correlation and regression are used to investigate the association of risk factors with fasting blood glucose. Results: Prevalence of Type 2 diabetes is at $0.9 \%(95 \% \mathrm{CI} ;[0.3,2.1])$ and impaired fasting tolerance at $2.4 \%(95 \% \mathrm{CI} ;[1.3,4.1])$. Fasting blood glucose is positively $(p<0.05)$ associated with body mass index, weight, waist circumference, systolic blood pressure, diastolic blood pressure, heart rate, main work but negatively associated with number of fruit intake days per week. Conclusion: The prevalence of Type 2 diabetes and Impaired Fasting Glucose is low in this particular sub-population which presents an opportunity for prevention. For successful prevention of diabetes among Maasai in Simanjiro District, programs should be tailored on reduction of obesity, blood pressure, and encouragement of consumption of fruits.
\end{abstract}

\section{Keywords}

Type 2 Diabetes, Maasai, Rural, Tanzania, WHO STEPWISE, Impaired Fasting Glucose

How to cite this paper: Mandha, J., Joram, B., Kassimu, N. and Petrucka, P. (2015) Risk Factors of Type 2 Diabetes among Maasai Pastoral Communities in Simanjiro, Tanzania. Open Access Library Journal, 2: e2079.

http://dx.doi.org/10.4236/oalib.1102079 


\section{Introduction}

Approximately 285 million people, 6.4\% between 20 - 79 years were found to be diabetic in 2010 worldwide [1]. The number is estimated to increase to 438 million (7.7\% of the adult population) by 2030 [1]. Diabetes is a chronic, metabolic disease which is evidenced by elevated blood glucose levels. Type 2 diabetes (T2D) is the most common and rapidly growing form of diabetes, which usually emerges during adulthood and is often associated with lifestyle issues. According to the International Diabetes Federation [1], T2D is either due to insufficient insulin or insulin resistance which lead to excess glucose in the blood which potentially leads to multi-system often life threatening complications including cardiovascular and renal diseases, retinopathies, and neuropathies. Risk factors for T2D are often lifestyle related, such as obesity, inactivity, and diet; antithetically leading to delayed recognition of the disease, while contributing to the potential of lifestyle change as a means to manage it.

The current national prevalence of diabetes in Tanzania is at 7.95\% [2]. The majority (90\%) of the people with diabetes in sub-Saharan Africa are undiagnosed [2] which has jettisoned this condition to be a health priority not only in this region, but globally [3]. Diabetes threatens the economic security and physical health of Tanzania [3] as it leads to complications such as atherosclerosis, renal failure, diabetic neuropathy (nerve dysfunction), and cerebrovascular disease [4]. These conditions significantly contribute to disability, reduced life expectancy and high health costs [5].

Non modifiable risk factors of T2D identified in sub-Saharan Africa are age, ethnicity, and gender, whereas the modifiable factors include physical activity, dietary intake, smoking, alcohol consumption and weight [6]. The cultural, social and economic conditions that produce these risk factors vary across different populations [7]. The Maasai, a pastoral ethnic group living in Northeastern Tanzania mainly feed on animal products such as meat, milk and blood [8]. A recent study reports a higher prevalence of T2D among the Maasai living in peri-urban (22.9\%) than in the rural areas (9.9\%) [9]. This finding is attributed, in part, to the adaptation of the rural Maasai shifting from traditional lifestyles in the Ngorongoro Conservation Area (NCA) as they move for employment and quality of life opportunities.

The current study is undertaken to investigate the risk factors of T2D and their association with Impaired Fasting Glucose (IFG) or T2D among rural Maasai communities in Simanjiro District, Tanzania.

\section{Methods}

\subsection{Study Setting and Population}

This was a cross-sectional population based study carried out in Simanjiro District. Simanjiro district is located in northern Tanzania, Manyara region. It is bordered to the north by Arusha region. Simanjiro District is mainly inhabited by the Maasai who are predominately livestock keepers. This group is unique in that they have lived in a highly traditional manner, including dietary practices, pastoral activities, and culturally informed lifestyles. The Maasai are a tribe which has increasingly been challenged for survival due to land disputes, environmental challenges, animal husbandry practices, and urbanization trends. As a result, they are only now beginning to experience lifestyle changes to more sedentary and Westernized ways which place them at the cusp of facing health challenges including non-communicable diseases.

The current study was conducted from March to July 2015 and the sample was drawn from five villages in Simanjiro; Olerumo, Irukujit, Mukumbi, Narosoito and Madukani. All Maasai adults aged 25 years and above living in the study areas were invited to participate. Non-consenting and individuals who were bedridden were excluded from this study. Multistage stratified cluster sampling was used, with a cluster being a household. The households were selected randomly. Using the Kish method individuals to be enrolled in the study was selected. The standard formula for epidemiological studies $n=\left[Z^{2} * p *(1-p)\right] / d^{2}$ was used to calculate sample size; where $n$ is the number of the sample, $d$ is margin of error, and $p$ is the planned proportion estimate population [10]. The level of confidence and margin of error used were $95 \%$ and 0.05 , respectively. An analytic study sample of 561 individuals was utilized. 


\subsection{Ethical Considerations}

This study was approved by the National Institute of Medical Research of Tanzania. Permission to conduct the study was sought from the respective local authorities such as district leaders, village leaders, and boma (clan) heads where the study was conducted. The goals and benefits of the study were explained to the participants prior to commencement of the study. An oral informed consent was obtained from each participant and information obtained was kept confidential. All participants received personal feedback of their physical and biochemical measurements and were referred to Simanjiro Health Center where necessary.

\subsection{Definitions}

Type 2 diabetes was defined as fasting capillary blood glucose $\geq 7.0 \mathrm{mmol} / \mathrm{L}$ and/or on diabetes medication (insulin and/or anti-diabetic drugs) while IFG was considered when blood glucose was found between 5.6 to 6.9 $\mathrm{mmol} / \mathrm{L}$ [11]. Hypertension was defined as systolic blood pressure (SBP) $\geq 140 \mathrm{~mm}$ Hg or diastolic blood pressure (DBP) is $\geq 90 \mathrm{mmHg}$, or both, on repeated examination [12] and or on hypertensive medication.

\subsection{Data Collection and Management}

Face to face interviews were conducted by trained interviewers including a health practitioner. Information obtained were anthropometric measurements, blood pressure, blood samples for biochemical analysis and selfreported behavioral and lifestyle factors using standardized procedures. All the instruments used were calibrated and adherence of trained interviewers to standardized procedures was monitored.

\subsubsection{Determination of Blood Sugar}

Fasting blood glucose was tested after an overnight fast of at least 8 hours using Gluco-plus ${ }^{\mathrm{TM}}$ meter. The middle finger without a ring was cleaned with an alcohol cotton swab and pricked with a lancet. Blood was collected on a glucose strip, inserted into the meter and watched as the results displayed immediately. The meter was calibrated using the control solution once every week. The results were verified by clinical technicians.

\subsubsection{Qualitative Data}

The WHO STEPWISE instrument, developed and implemented by the World Health Organization, was used to identify T2D risk factors [13]. Since 2008, the WHO STEPWISE approach has targeted launching surveillance of chronic diseases and their risk factors in low and middle income countries. This program is aimed at helping these countries in their early surveillance efforts as they build and strengthen their capacities related to noncommunicable disease surveillance [13]. The standardized questionnaire was administered in Swahili (national language of Tanzania) by trained interviewers. However, Kimaasai was used where Swahili was unknown. Questions on smoking habits, alcohol intake, physical activity, diet, history of diabetes (if already told by a doctor to be diabetic and/or on diabetes treatment) and demographic data were asked. The instrument was pre-tested and revised prior to commencement of the study.

\subsubsection{Determination of Blood Pressure}

Blood pressure was measured using standardized protocol with the respondent in a seated position and after a 10 minute rest. The automatic calibrated digital blood pressure measurement system (Omron ${ }^{\mathrm{TM}}$ Digital HEM-7000, Tokyo, Japan) was used. An average of two readings taken 1 minute apart was used for analysis.

\subsubsection{Anthropometric Measurements}

Weight, height, waist circumference, and hip circumference were measured using standard methods. Standing height was measured using a stadiometer at a $0.5 \mathrm{~cm}$ precision. Weight was measured using an electronic scale at $0.1 \mathrm{~kg}$ precision with the participant in light clothing. The hip region was the widest part of the buttocks, lower to the iliac crest [14]. Hip circumference was measured to the nearest $0.1 \mathrm{~cm}$. Waist circumference (WC) (to the nearest $0.1 \mathrm{~cm}$ ) was measured using a stretch-resistant tape measure between the lower rib margin and the iliac crest after several consecutive natural breaths [15].

Obesity was determined using body mass index (BMI), WC and waist to hip ratio (WHR). Body mass index was calculated as weight $(\mathrm{kg})$ divided by squared height $\left(\mathrm{m}^{2}\right)$. A participant was considered normal with BMI 
between $18.5 \mathrm{~kg} / \mathrm{m}^{2}$ and $25 \mathrm{~kg} / \mathrm{m}^{2}$, overweight between $25 \mathrm{~kg} / \mathrm{m}^{2}$ and $30 \mathrm{~kg} / \mathrm{m}^{2}$, and obese with BMI $\geq 30 \mathrm{~kg} / \mathrm{m}^{2}$ [16]. Men and women with waist circumference $\geq 94 \mathrm{~cm}$ and $\geq 80 \mathrm{~cm}$ respectively were to be at risk of central obesity according to the International Diabetes Federation guidelines for metabolic syndrome among sub-Saharan Africans [17]. Waist to hip ratio was analyzed by taking waist/hip measurement. Presence of abdominal obesity was considered when WHR $>0.90$ for men and $>0.85$ for women.

\subsection{Data Analysis}

The data was analyzed using Graph Pad PrismM Software Version 6 (Graph Pad ${ }^{\mathrm{TM}}$ Software Inc., USA). Descriptive statistics were used to explore prevalence and risk factors of T2D and IFG. Means and standard deviations (SD) were used for continuous variables. Pearson's correlation and linear regression analysis were carried out to determine association of select predictors with diabetes. Predictors included gender, BMI, weight, height, age, WC, smoking, dietary intake (fruits and vegetables) and physical activity. A $p$-value $<0.05$ was interpreted as statistically significant result.

\section{Results}

\subsection{Demographic Characteristics}

A total of 561 respondents were involved in this study of whom $68.8 \%$ were women and $31.2 \%$ men. More respondents were in the age group 25 - 34 years (46.9\%), whereas 54 - 64 year olds were the least represented (16.7\%). The complete demographic profile is reflected in Table 1, which shows that participants were generally younger, married, minimally educated individuals.

\subsection{Prevalence of $T 2 D$ and IGT}

Overall, the prevalence of T2D was found to be $0.9 \%$ (1.1\% men and $0.8 \%$ women) and IFG at 2.5\% (2.9\% men and $2.3 \%$ women) as shown in Figure 1. There was no significant difference $(p=0.08)$ the prevalence of diabetes between men and women and across the age groups (Figure 2). Participants aged 65+ had the highest IFG and T2D prevalence at $7.1 \%$ and $2.3 \%$ respectively.

\subsection{Type 2 Diabetes Risk Factors}

To investigate the risk factors of T2D in Simanjiro District, the association of different risk factors with fasting blood glucose (FBG) was computed using correlation and linear regression. Fasting blood glucose was positively $(p<0.05)$ associated with BMI, weight, WC, SBP, DBP, heart rate, and main work. The number of fruit intake days per week was found to be negatively associated with FBG.

\subsubsection{Body Mass Index}

A significant proportion (61.3\%) of the Maasai was of normal weight, with an additional $23.1 \%$ being overweight (Figure 3). There was a significant difference in the BMIs of participants in the different age groups ( $p=$ 0.0354) (Figure 4). The 65+ had the highest BMI in men (25.0 \pm 5.13$)$ and women (25 \pm 5.7$)$. The $35-44$ age

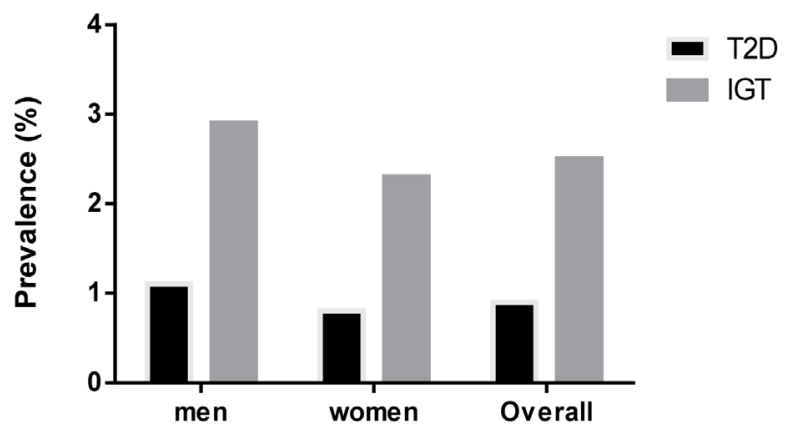

Figure 1. Prevalence of Type 2 diabetes and impaired fasting glucose among Maasai in Simanjiro District. 
Table 1. Description of Maasai participants in Simanjiro District.

\begin{tabular}{|c|c|c|c|c|c|c|}
\hline \multirow{2}{*}{ Socio demographic characteristics } & \multicolumn{2}{|c|}{ IFG/T2D } & \multicolumn{2}{|c|}{ NON IFG/T2D } & \multicolumn{2}{|c|}{ TOTAL } \\
\hline & $\mathbf{N}$ & $\%$ & $n$ & $\%$ & $n$ & $\%$ \\
\hline \multicolumn{7}{|l|}{ Gender } \\
\hline Men & 7 & 36.8 & 168 & 31 & 175 & 31.2 \\
\hline Women & 12 & 63.2 & 374 & 69 & 386 & 68.8 \\
\hline \multicolumn{7}{|l|}{ Age group (years) } \\
\hline $25-34$ & 10 & 52.6 & 253 & 46.7 & 263 & 46.9 \\
\hline $35-44$ & 3 & 15.8 & 147 & 27.1 & 150 & 26.7 \\
\hline $45-54$ & 2 & 10.5 & 61 & 11.3 & 63 & 11.2 \\
\hline $55-64$ & 0 & 0.0 & 42 & 7.7 & 42 & 7.5 \\
\hline $65+$ & 4 & 21.1 & 39 & 7.2 & 43 & 7.7 \\
\hline \multicolumn{7}{|l|}{ Marital status } \\
\hline Currently married & 15 & 78.9 & 492 & 90.8 & 507 & 90.4 \\
\hline Never married & 0 & 0 & 21 & 3.9 & 21 & 3.7 \\
\hline Widowed & 3 & 15.8 & 26 & 4.8 & 29 & 5.2 \\
\hline Separated & 1 & 5.3 & 1 & 0.2 & 2 & 0.4 \\
\hline Cohabiting & 0 & 0 & 2 & 0.4 & 2 & 0.4 \\
\hline \multicolumn{7}{|l|}{ Education level } \\
\hline No formal schooling & 14 & 73.7 & 315 & 58.1 & 329 & 58.6 \\
\hline Primary school completed & 1 & 5.3 & 150 & 27.7 & 151 & 26.9 \\
\hline$<$ Primary school & 1 & 5.2 & 18 & 3.3 & 19 & 3.4 \\
\hline Secondary school completed & 1 & 5.2 & 32 & 5.9 & 33 & 5.9 \\
\hline$<$ Secondary school & 2 & 10.5 & 22 & 4.1 & 24 & 4.3 \\
\hline College completed & 0 & 0.0 & 5 & 0.9 & 5 & 0.9 \\
\hline \multicolumn{7}{|l|}{ Ever Smoked } \\
\hline Yes & 15 & 78.9 & 68 & 12.5 & 83 & 14.8 \\
\hline No & 4 & 21.1 & 474 & 87.5 & 478 & 85.2 \\
\hline \multicolumn{7}{|l|}{ Ever consumed alcohol } \\
\hline Yes & 2 & 10.5 & 45 & 8.3 & 47 & 8.4 \\
\hline No & 17 & 89.5 & 497 & 91.7 & 514 & 91.6 \\
\hline \multicolumn{7}{|l|}{ Physical activity } \\
\hline Inactive (WHO < 600 METs) & 0 & 0 & 22 & 40.6 & 22 & 3.9 \\
\hline Active (WHO $\geq 600$ METs) & 19 & 100 & 520 & 95.9 & 539 & 96.1 \\
\hline
\end{tabular}




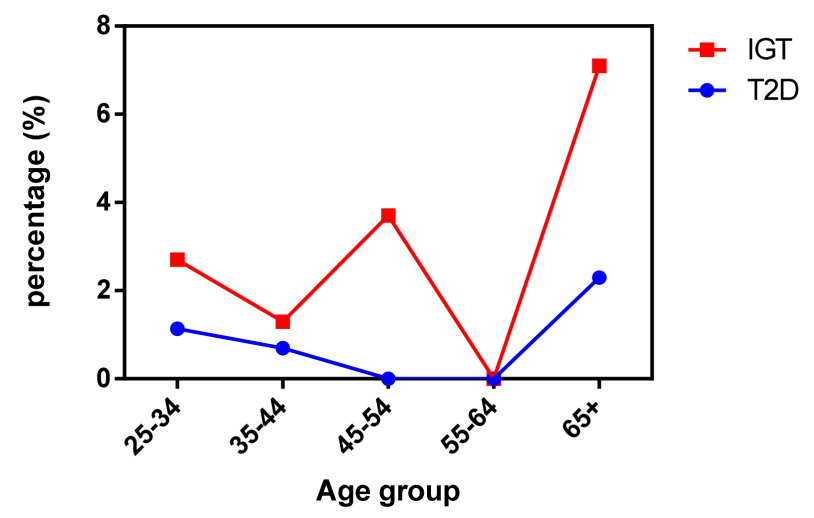

Figure 2. Prevalence of type 2 diabetes and impaired fasting glucose of Maasai across age groups in Simanjiro District.

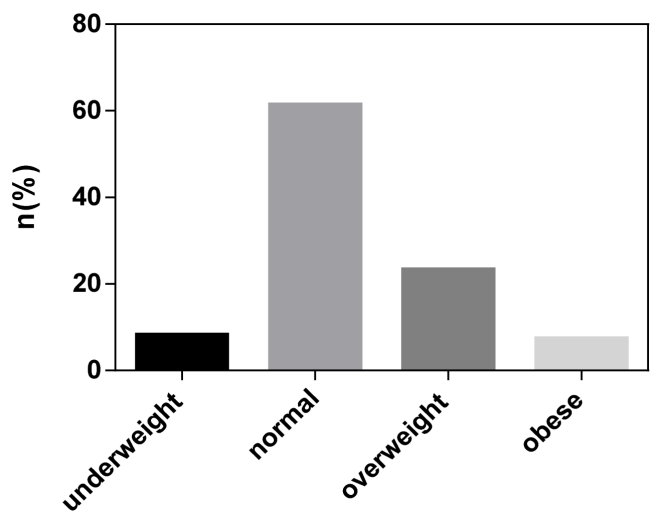

Figure 3. Body mass index of Maasai participants in Simanjiro District.

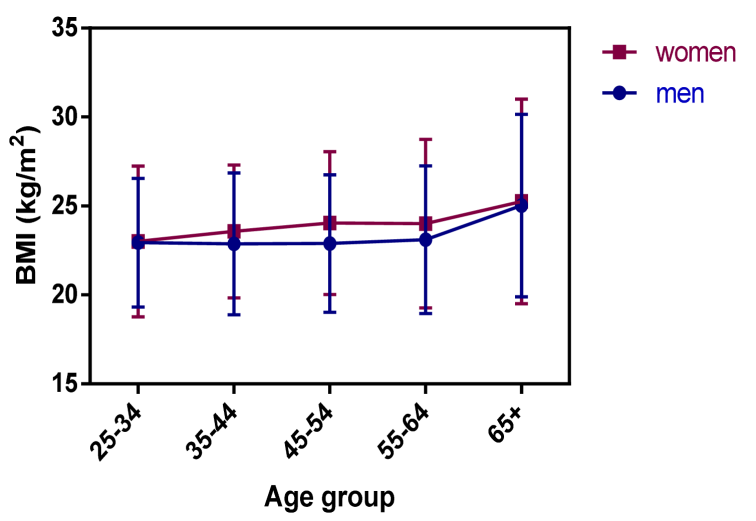

Figure 4. Body mass index of the Maasai of different age groups in Simanjiro District.

group had the lowest BMI in men (22.86 \pm 3.98$)$ and the 25 - 34 group was the lowest in women $(23.0 \pm 4.23)$. There was no significant difference $(p=0.19)$ in the BMI of men and women (Table 2).

\subsubsection{Waist Circumference (WC)}

Nearly half of the women (42.5\%) were at risk of central obesity as compared to $13.7 \%$ of the men. There was no significant difference $(p=0.69)$ in the WC of men and women and across age groups (Figure 5). Men had a mean WC of $79.3 \pm 12.0$ similarly, women recorded a mean WC of $79.2 \pm 12.2$. 


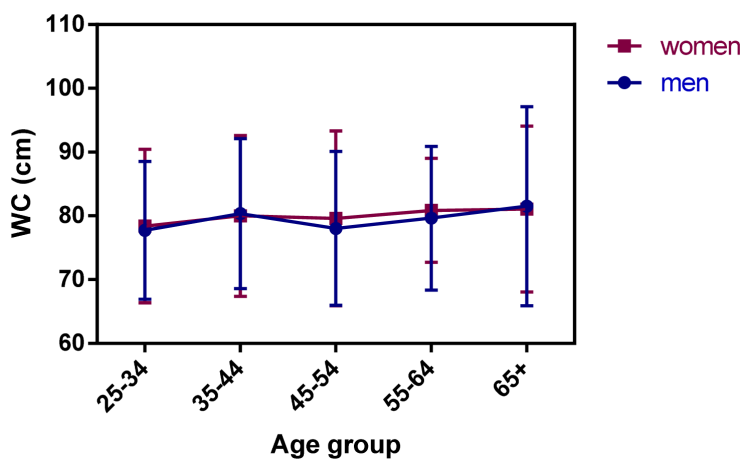

Figure 5. Waist circumference of Maasai men and women in Simanjiro District.

Table 2. Pearson's correlation and regression analysis for determinants of fasting blood glucose.

\begin{tabular}{ccccc}
\hline \multirow{2}{*}{ Risk factor } & \multicolumn{2}{c}{ Pearson's correlation } & \multicolumn{2}{c}{ Linear regression } \\
\cline { 2 - 5 } & Correlation coefficient (R) & $\boldsymbol{P}$ & $\mathbf{R}^{2}$ & Linear equation \\
\hline Weight $(\mathrm{kg})$ & 0.1528 & $0.0003^{* * *}$ & 0.0234 & $\mathrm{Y}=3.452 * \mathrm{X}+46.89$ \\
BMI $\left(\mathrm{kg} / \mathrm{m}^{2}\right)$ & 0.1677 & $<0.0001^{* * * *}$ & 0.0281 & $\mathrm{Y}=1.292 * \mathrm{X}+17.64$ \\
Waist circumference $(\mathrm{cm})$ & 0.1093 & $0.0115^{*}$ & 0.0120 & $\mathrm{Y}=2.514 * \mathrm{X}+68.03$ \\
Systolic Blood pressure & 0.1340 & $0.0015^{* *}$ & 0.0180 & $\mathrm{Y}=4.506 * \mathrm{X}+100.9$ \\
Diastolic blood pressure & 0.1391 & $0.0010^{* * *}$ & 0.0194 & $\mathrm{Y}=2.858 * \mathrm{X}+67.06$ \\
Heart rate & 0.1065 & $0.0116^{*}$ & 0.0113 & $\mathrm{Y}=2.437 * \mathrm{X}+66.03$ \\
No of fruit days & -0.1074 & $0.0109^{*}$ & 0.0115 & $\mathrm{Y}=-0.3245 * \mathrm{X}+3.291$ \\
Main Work & 0.0893 & $0.0346^{*}$ & 0.0080 & $\mathrm{Y}=0.3886 * \mathrm{X}+2.783$ \\
\hline
\end{tabular}

BG:blood glucose; BMI:body mass index.

\subsubsection{Blood Pressure}

$3.7 \%$ of the participants had a history of raised blood pressure. There was no significant difference $(p=0.29)$ in the SBP of men and women and across the age groups (Figure 6). Men had a SBP of $123.85 \pm 18.35$ and women $120.15 \pm 17.96$.

\subsubsection{Heart Rate}

There was a significant difference $(p=0.0036)$ in the heart rate of men and women (Figure 7). Women had a higher heart rate $(77.99 \pm 12.7)$ than men $(74.34 \pm 11.7)$. There was no significant difference $(p=0.26)$ in the heart rate cross the age groups.

\subsubsection{Fruit Consumption}

Generally, the mean frequency of fruit consumption was $1.8 \pm 1.6$ times per week. There was a significant difference in the fruit consumption of men and women $(p=0.0012)$. Women had a tended to consume more fruits $(2 \pm 0.08)$ than men $(1.5 \pm 0.12)$ per week.

\section{Discussion}

Type 2 diabetes has become a health priority in sub-Saharan Africa and continues to be a substantial public health problem worldwide [3]. Diabetes may result to disability, reduced life expectancy and high health costs [18]. The Maasai are a Nilotic ethnic group of nomads having a unique lifestyle and culture which may make them susceptible to T2D. They mainly consume animal products in particular meat, blood and milk [8]. A recent study compared prevalence of T2D among Maasai in rural (NCA)) and urban (Arusha City) and found marked 


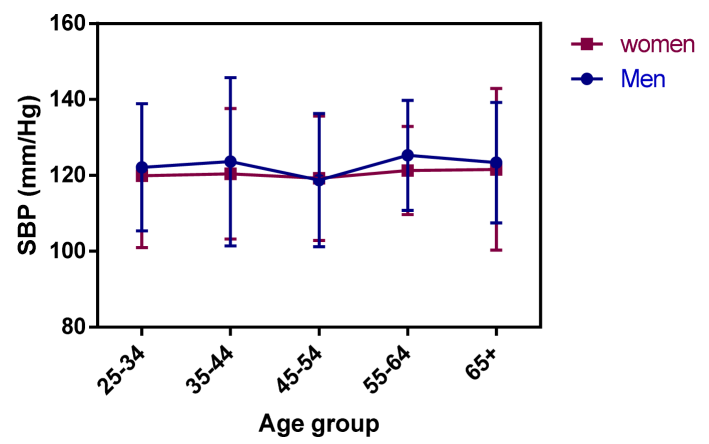

Figure 6. Systolic blood pressure across the age groups of Maasai in Simanjiro.

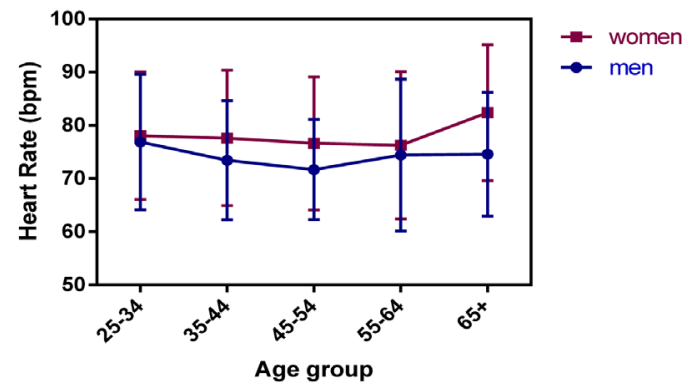

Figure 7. Heart Rate of Maasai participants in Simanjiro District across the age groups.

differences between the two groups [9]. However, it was argued that the results obtained may not be representative of other rural Maasai living elsewhere. This is because the Maasai in NCA have high food shortages, cultivate and have reduced number of livestock due to the restrictive living regulations of NCA hence deviating from their traditional lifestyle. This study therefore focused on rural pastoral Maasai ethnic community in Simanjiro District in Tanzania.

In this current study, the prevalence of T2D and IFG among the rural Maasai in Simanjiro District were at 0.9\% ( $1.1 \%$ men and $0.8 \%$ women) and $2.5 \%$ (2.9\% men and $2.3 \%$ women) respectively. The prevalence of T2D observed was much lower $(0.9 \%)$ than that reported for rural Maasai in NCA $(9.9 \%)$ [9]. This pattern may be due to the diversification of the diet in the rural Maasai in NCA as compared to the Maasai in Simanjiro District. Compared to other rural settings in Tanzania, our finding was similar to the low diabetic prevalence (1.5\%) and IGT (1.2\%) in Shari [19] but different from rural communities in Arumeru (T2D 9\%, IFG 7.1\%) [20]. The Maasai in the urban were reported to have a high T2D prevalence of 22.9\% [9]. Other studies in urban settings also reported a high T2D prevalence of 11.9\% [21] in Mwanza city, 9.8\% among Hindu communities in Dar es Salaam [22] and 5.3\% in Ilala [20]. This may be due to lifestyle changes due to urbanization.

Fasting blood glucose was positively associated with obesity indicators (BMI, weight, and WC), SBP, DBP, heart rate, and main work. This is consistent with findings in other studies in Tanzania [9] [22]. Conversely, the number of fruit intake days per week was negatively associated with T2D.

Overweight and obesity are a major risk factor of chronic diseases such as T2D. Fasting blood glucose was positively associated with BMI and WC which are measures of overweight and obesity. This was similar to the rural and urban Maasai in NCA and Arusha city respectively [9]. Overweight and obesity are associated with low grade inflammation characterized by increased circulating pro-inflammatory cytokines and fatty acids. These interfere with normal insulin function inducing insulin resistance and eventually $\beta$ cell dysfunction [23]. Most participants were found to be of normal weight which may be attributable to the high physical activity levels of the Maasai in Simanjiro District.

Diabetes and hypertension have been shown to coexist [24]. Hypertension accelerates diabetic complications. Diabetes damages and hardens the arteries which may contribute to high blood pressure. Elevation of insulin levels, insulin resistance, and metabolic syndrome adds oxidative stress leading to endothelial dysfunction a key 
component of hypertension [25]. Fasting blood glucose was positively associated with hypertensive SBP and DBP readings. This finding was consistent with the Maasai from Arusha city but not from NCA [9].

Greater consumption of whole fruits has been associated with reduced risk of T2D [26]. Fruit consumption was negatively associated with FBG among the Maasai. Fruit intake reduces the risk of weight gain which is a major risk factor for diabetes [27].

\section{Conclusion}

The present study investigated the risk factors of T2D among the rural Maasai community in Simanjiro District. Results demonstrated the prevalence of T2D and IFC among the rural Maasai to be low. This finding showed an opportunity for prevention. For successful prevention of diabetes among Maasai, programs should be tailored towards reduction of obesity, blood pressure, and promotion of consumption of fruits.

\section{Acknowledgements}

We acknowledge the African Capacity Building Foundation for funding this research.

\section{Competing Interest}

Authors have declared that no competing interests exist.

\section{References}

[1] International Diabetes Federation (2013) The Global Burden. 6th Edition, International Diabetes Federation Diabetes Atlas, 29-49. https://www.idf.org/sites/default/files/EN_6E_Atlas_Full_0.pdf

[2] Aguiree, F., Brown, A., Cho, N., Dahlquist, G. and Whiting (2013) IDF Diabetes Atlas. In: Guariguata Leonor, J.O., Tim, N., Jessica, B. and Ute, L., Eds., IDF Diabetes Atlas, 6th Edition, International Diabetes Federation, Basel, 74-90.

[3] World Bank (2011) The Growing Danger of Non-Communicable Diseases: Acting Now to Reverse Course. http://documents.worldbank.org/curated/en/2011/09/15512807/growing-danger-non-communicable-diseases-acting-no w-reverse-course

[4] Fowler, M.J. (2011) Microvascular and Macrovascular Complications of Diabetes. Clinical Diabetes, 29, 116-122. http://dx.doi.org/10.2337/diaclin.29.3.116

[5] Shaw, J., Sicree, R. and Zimmet, P. (2010) Global Estimates of the Prevalence of Diabetes for 2010 and 2030. Diabetes Research and Clinical Practice, 87, 4-14. http://www.sciencedirect.com/science/article/pii/S016882270900432X http://dx.doi.org/10.1016/j.diabres.2009.10.007

[6] Mbanya, J.C.N., Motala, A.A., Sobngwi, E., Assah, F.K. and Enoru, S.T. (2010) Diabetes in Sub-Saharan Africa. The Lancet, 375, 2254-2266. http://dx.doi.org/10.1016/S0140-6736(10)60550-8

[7] Unwin, N., Setel, P., Rashid, S., Mugusi, F., Mbanya, J.C., Kitange, H., Hayes, L., Edwards, R., Aspray, T. and Alberti, K.G. (2001) Noncommunicable Diseases in Sub-Saharan Africa: Where Do They Feature in the Health Research Agenda? Bulletin of the World Health Organization, 79, 947-953.

[8] Brady, R., Suksiri, S., Tan, S., Dodds, J. and Aine, D. (2008) Current Health and Environmental Status of the Maasai People in Sub-Saharan Africa. California Polytechnic Honors Undergraduate Research Journal, 1, 17-32. http://digitalcommons.calpoly.edu/honors/vol1/iss1/6

[9] Masaki, S., Ngoye, A., Petrucka, P. and Buza, J. (2015) Type 2 Diabetes Prevalence and Risk Factors of Urban Maasai in Arusha Municipality and Rural Maasai in Ngorongoro Crater. Journal of Applied Life Sciences International, 3, 157-168. http://dx.doi.org/10.9734/jalsi/2015/20174

[10] Kasiulevičius, V., Šapoka, V. and Filipavičiūtè, R. (2006) Sample Size Calculation in Epidemiological Studies. Gerontologija, 7, 225-231.

[11] World Health Organization (2006) Definition and Diagnosis of Diabetes Mellitus and Intermediate Hyperglycemia.

[12] Weber, M.A., Schiffrin, E.L., White, W.B., Mann, S., Lindholm, L.H., Kenerson, J.G., et al. (2014) Clinical Practice Guidelines for the Management of Hypertension in the Community: A Statement by the American Society of Hypertension and the International Society of Hypertension. Journal of Clinical Hypertension, 16, 14-26. http://dx.doi.org/10.1111/jch.12237

[13] World Health Organization (2008) WHO STEPS Surveillance Manual. WHO Global Report, Geneva. http://apps.who.int/iris/bitstream/10665/43376/1/9241593830_eng.pdf 
[14] Lissner, L., Björkelund, C., Heitmann, B.L., Seidell, B. and Bengtsson, C. (2001) Larger Hip Circumference Independently Predicts Health and Longevity in a Swedish Female Cohort. Obesity Research, 9, 644-646. http://dx.doi.org/10.1038/oby.2001.85

[15] World Health Organization (1995) Physical Status: The Use and Interpretation of Anthropometry. Report of a WHO Expert Committee. Physical Status: The Use and Interpretation of Anthropometry. Report of a WHO Expert Committee. Technical Report Series No. 854.

[16] de Onis, M. and Habicht, J. (1996) Anthropometric Reference Data for International Use: Recommendations from a World Health Organisation Expert Committee. The American Journal of Clinical Nutrition, 64, 650-658. http://ajcn.nutrition.org/content/64/4/650.short

[17] Alberti, K.G., Eckel, R.H., Grundy, S.M., Zimmet, P.Z., Cleeman, J.I., Donato, K.A., et al. (2009) Harmonizing the Metabolic Syndrome: A Joint Interim Statement of the International Diabetes Federation Task Force on Epidemiology and Prevention. Circulation, 120, 1640-1645. http://dx.doi.org/10.1161/CIRCULATIONAHA.109.192644

[18] Sicree, R., Shaw, J., Zimmet, P. and Baker IDI Heart and Diabetes Institute (2009) The Global Burden: Diabetes and Impaired Glucose Tolerance.

[19] Aspray, F., Mugusi, S., Rashid, S. Whiting, D., Edwards, R., Alberti, K.G. and Unwin, N.C. (2000) Rural and Urban Differences in Diabetes Prevalence in Tanzania: The Role of Obesity, Physical Inactivity and Urban Living. Transactions of the Royal Society of Tropical Medicine and Hygiene, 94, 637-644. http://dx.doi.org/10.1016/S0035-9203(00)90216-5

[20] Miller, B.J. (2013) Type 2 Diabetes Mellitus in the Arumeru District of Northern Tanzania: Evaluation of the Prevalence and Associated Risk Factors in Rural Communities. Unpublished Dissertation. https://research.wsulibs.wsu.edu:8443/xmlui/handle/2376/4721

[21] Ruhembe, C.C., Mosha, T.C.E. and Nyaruhucha, C.N.M. (2014) Prevalence and Awareness of Type 2 Diabetes Mellitus among Adult Population in Mwanza City, Tanzania. Journal of Health Research, 16, 1-11. http://dx.doi.org/10.4314/thrb.v16i2.4

[22] Ramaiya, K.L., Swai, A.B., McLarty, D.G., Bhopal, R.S. and Alberti, K.G. (1991) Prevalences of Diabetes and Cardiovascular Disease Risk Factors in Hindu Indian Subcommunities in Tanzania. BMJ (Clinical Research Ed.), 303, 271276. http://dx.doi.org/10.1136/bmj.303.6797.271

[23] van Greenvenbroek, M.M., Schalkwijk, C.G. and Stehouwer, C.D. (2013) Obesity-Associated Low-Grade Inflammation in Type 2 Diabetes Mellitus: Causes and Consequences. Netherlands Journal of Medicine, 71, 174-187.

[24] Ferrannini, E. and Cushman, W.C. (2012) Diabetes and Hypertension: The Bad Companions. The Lancet, 380, 601610. http://dx.doi.org/10.1016/S0140-6736(12)60987-8

[25] Schutta, M.H. (2007) Diabetes and Hypertension: Epidemiology of the Relationship and Pathophysiology of Factors Associated with These Comorbid Conditions. Journal of the Cardiometabolic Syndrome, 2, 124-130. http://dx.doi.org/10.1111/j.1559-4564.2007.06368.x

[26] Muraki, I., Imamura, F., Manson, J.E., Hu, F.B., Willett, W.C., van Dam, R.M. and Sun, Q. (2013) Fruit Consumption and Risk of Type 2 Diabetes: Results from Three Prospective Longitudinal Cohort Studies. BMJ (Clinical Research Ed.), 347, f5001. http://dx.doi.org/10.1136/bmj.f5001

[27] Boeing, H., Bechthold, A., Bub, A., Ellinger, S., Haller, D., Kroke, A., Leschik-Bonnet, W., Muller, M.J., Oberriter H., Schulze, M., Stehle, P. and Watzl, B. (2012) Critical Review: Vegetables and Fruit in the Prevention of Chronic Diseases. European Journal of Nutrition, 51, 637-663. http://dx.doi.org/10.1007/s00394-012-0380-y 


\section{Abbreviations}

BMI: Body Mass Index

DBP: Diastolic Blood Pressure

FBG: Fasting Blood Glucose

IFG: Impaired Fasting Glucose

NCA: Ngorongoro Conservation Area

SBP: Systolic Blood Pressure

SD: Standard Deviation

T2D: Type 2 Diabetes

WC: Waist Circumference

WHO: World Health Organization

WHR: Waist to Hip Ratio 